\title{
The social-psychological satiety: empirical study of new phenomenon
}

I.V. Larionov, State Academic University for the Humanities

T.V. Drobysheva, FSFES Institute of Psychology, Russian Academy of Sciences

Phenomena of city environment acts as an object of research in different areas of psychology - social psychology, psycholinguistics, clinical psychology, psychology of perception etc. Analysis of psychological researches clearly shows, that in recent time psychologists are interested in research of psychological effects of living in modern city. Phenomenon of socialpsychological satiety of such living conditions can be positioned as one of the main objects for this new direction of research. Within this new social-psychological approach to research of this phenomenon it is necessary to pay attention on search and analysis of it's sources in city environment. Actuality of research of socialpsychological satiety is due to constant growth of urbanization process worldwide.

Social-psychological satiety as a condition of the human psyche perform the function of a protective mechanism from an overabundance of a flow of various stimuli from the surrounding world.

Purpose of the research: distinguish and analyze severity of social-psychological satiety with the living conditions in correlation with sources of this condition.

Methods of research: focus group method to discuss phenomena of social-psychological satiety (assessments from focus group were used to construct author questionnaires), associative test (results were used to determine the structure of social representation about social-psychological satiety, according to prototypical analysis of $\mathrm{P}$. Verges), statistica methods
Structure and content of social representation of satiety among young moscovities.

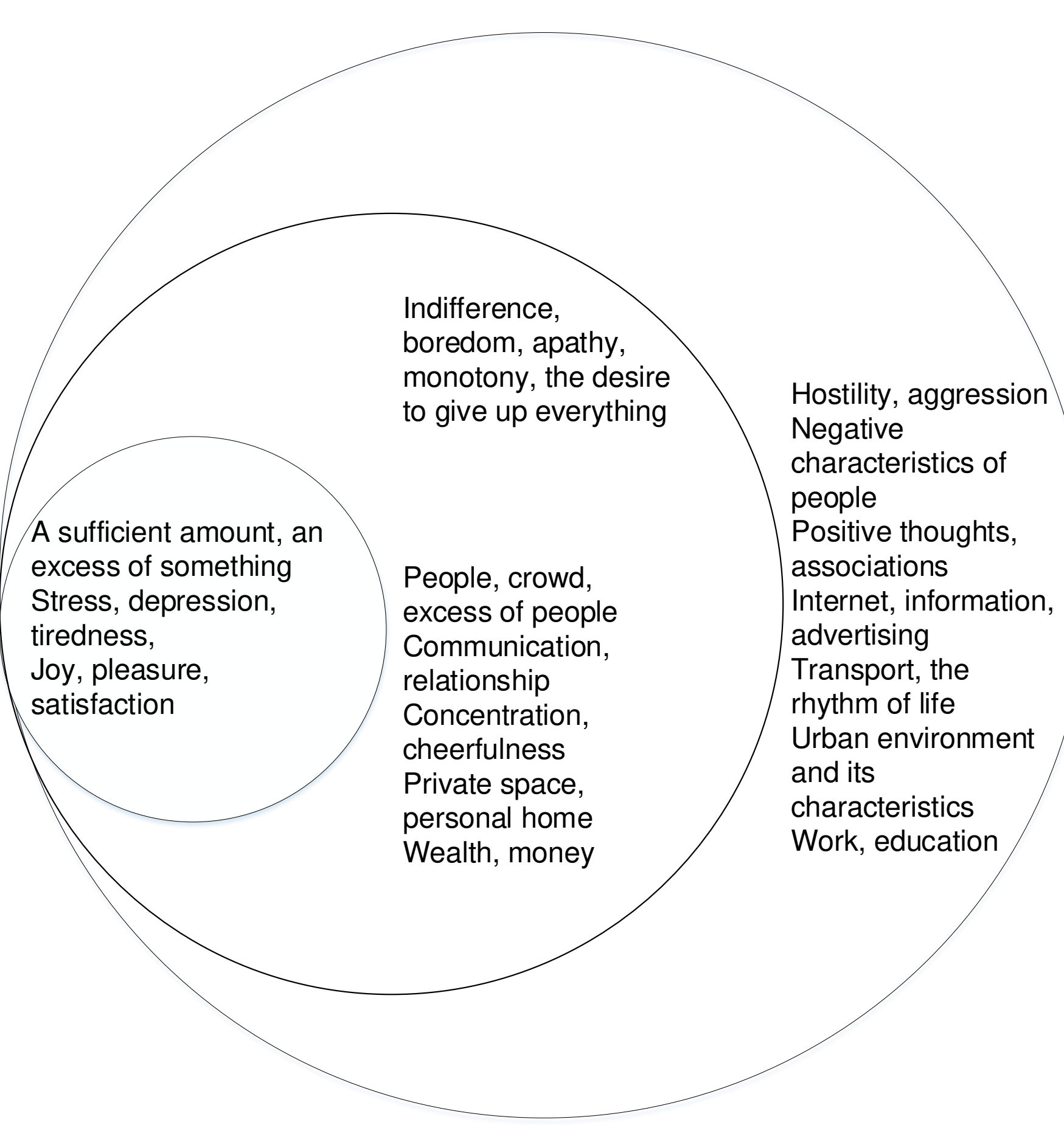

Results show, that understanding of satiety in group of respondents is stereotypical - young people interpret it literally - they describe big amount of different stimulus, as manifestations of urban environment (social, spatial, informational environment), sufficient amount of something), ambivalent in understanding of emotional aspect and includes sources of social-psychological satiety with the living conditions
Correlations between manifestations $(\mathrm{M})$ and sources $(\mathrm{S})$
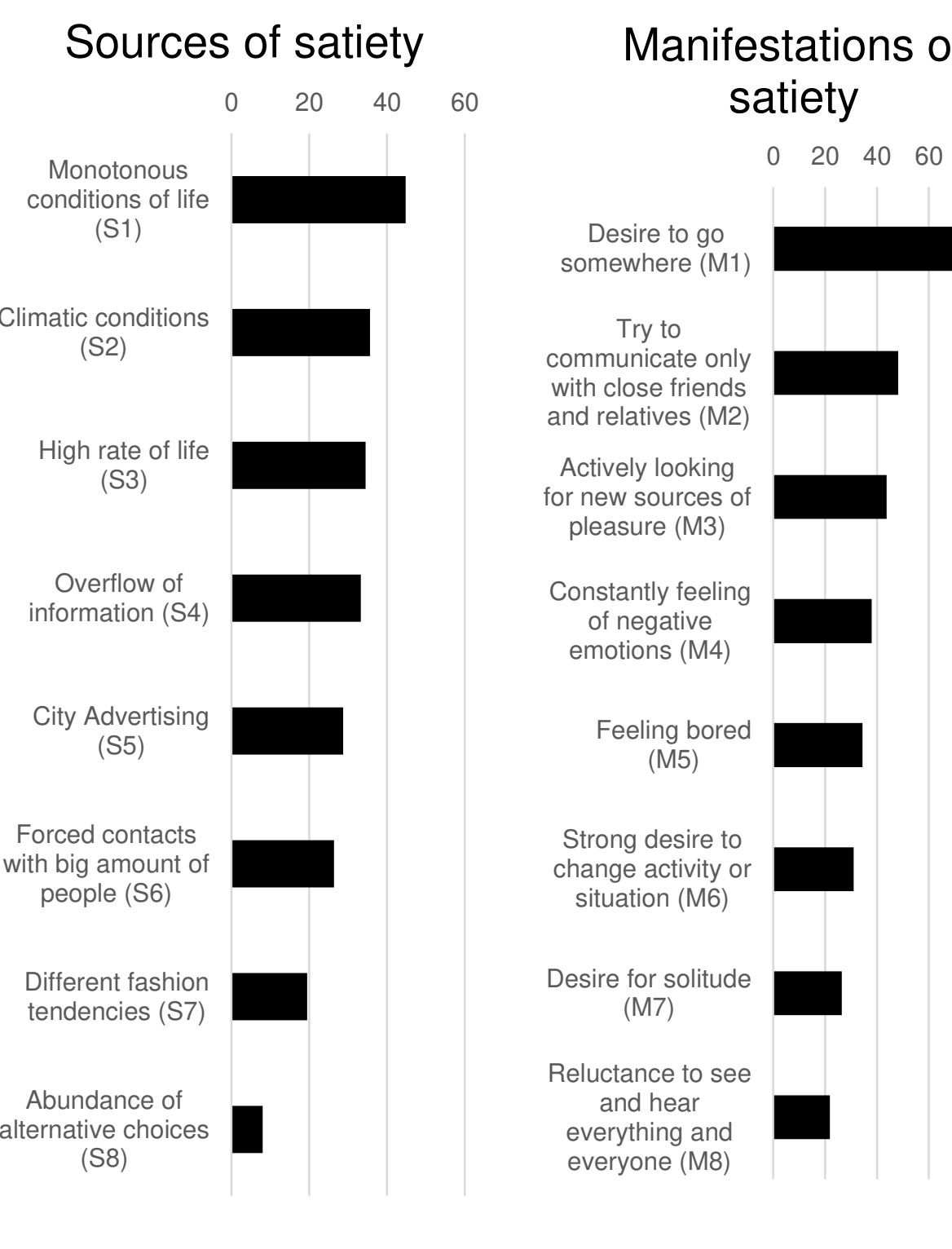

Correlations

between manifestations and sources (r-Spearman)

We can disti
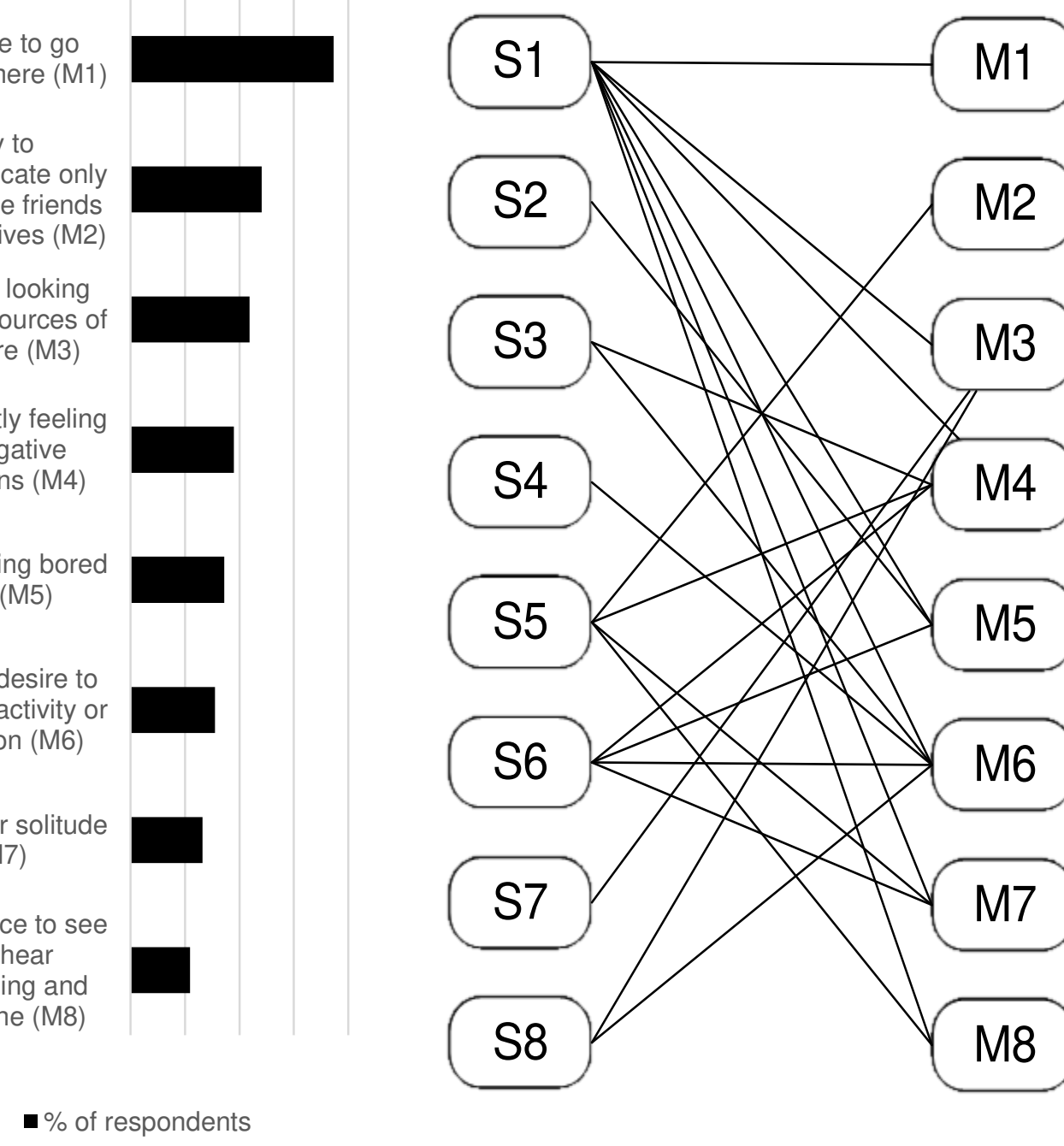

distinguish several forms of social-psychological satiety:

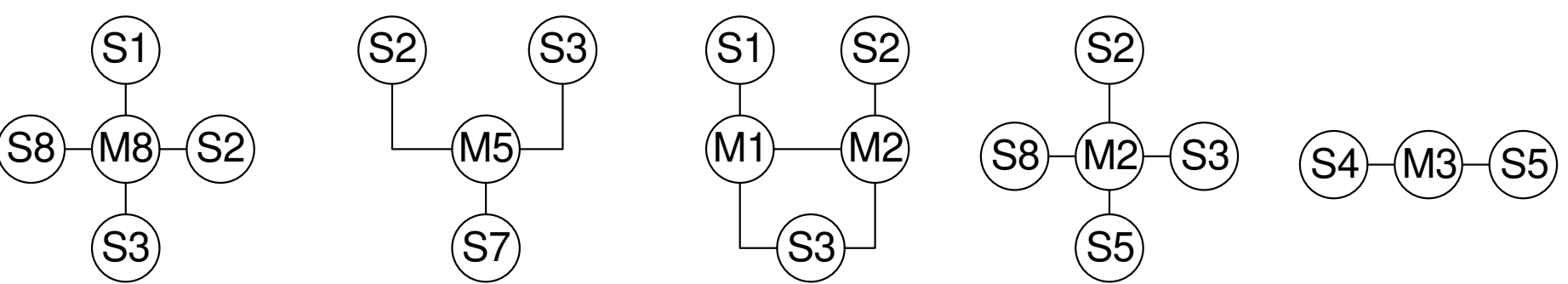

Analysis of data allowed to distinguish several forms of satiety, as emotional expressions and behavioral attitudes. Both forms are caused by high rate of life monotony of life, weather conditions, excessive social contacts. But behaviora attitudes are also caused by abundance of different pastime opportunities, goods services etc.

Conclusion

Social-psychological satiety is complex phenomenon, clearly manifested in the urban environment and entailing a number of negative mental effects that threaten the individual's physical, social and psychological well-being.

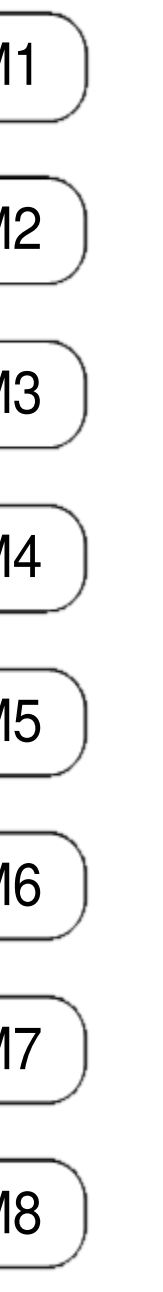

